\title{
POÉTICAS DE LA CLARIDAD O DEL ARTIFICIO EN LA SERIE LITERARIA ESPAÑOLA
}

FRANCISCO ABAD

UNED

fabad@flog.uned.es

Fecha de recepción: 23-11-2017

Fecha de aceptación: 30-11-2017

\section{RESUMEN}

Tratamos de la sucesión estilística de épocas clasicistas (épocas A), y épocas de complicación elocutiva (B).

Palabras Clave: Góngora, Lope, Ramón Menéndez Pidal, Dámaso Alonso.

RÉSUMÉ

Dans cet article on aborde la question de la succession stylistique d'époques classiques (époques A) et d'époques de complication de l'élocution (époques B).

Mots-Clefs: Góngora, Lope, Ramón Menéndez Pidal, Dámaso Alonso.

0. Existe una hipótesis propuesta por la historiografía según la cual existen en el despliegue de lo humano fases históricas A o expansivas, y fases B de recesión: en la cultura se postula que las A se corresponden en general con el clasicismo estilístico y la claridad elocutiva, mientras las B se corresponden con estilos barrocos y la complicación y la oscuridad. 
Pero la historia de la lírica y las poéticas —y las historias en general— resultan complejas, y ese esquema inicial resulta en lo real bastante más matizado.

El XVI es clasicista y se corresponde con una fase histórica A; el Barroco es el estilo de una fase B; las décadas últimas del Ochocientos constituyen una fase B, y sin embargo los estilos son sencillos y hasta vulgares contra lo que se hubiera esperado.

En suma: para la historia de los estilos literarios, queda muy matizada la hipótesis de que sin más la elocución de claridad y clasicista se corresponde con una fase A, y la elocución difícil y hasta oscura se corresponde con una fase B.

Apuntamos por otra parte una revalorización — además de la usual del primer tercio del siglo XVII, y reformulando en parte a distintos autores-, de los años históricos, literarios y artísticos que van de 1635 a 1659.

\section{LOS ESTILOS DE ARTE VERBAL}

\subsection{La historia de los estilos como historia de la libertad del espíritu}

Una referencia capital en la historia de los análisis estilísticos — dentro de los estudios lingüísticos y literarios - es la de los dos volúmenes seguidos y complementarios de Karl Vossler Positivismo e idealismo en la lingüística y El lenguaje como creación y evolución, editados en Heidelberg en los años 1904 y 1905; ambos pretendieron un carácter programático y de ejemplo pionero, y así dejaron huella, pese a algunas reservas sobre el vosslerismo que expresaría lustros más tarde G. Rohlfs, etc.

Vossler llevó a cabo entonces una proclama fundamental: la de que la historia de los estilos que se plasma en las historias concretas lingüística y literaria, es la historia de la libertad del espíritu, de la libertad de los hablantes egregios o bien comunes, ordinarios. Sin duda nuestro autor se movía en la teorización que era un poco anterior de la filosofía alemana acerca de la ciencia del espíritu o ciencia cultural, a diferencia de la ciencia natural; las ciencias de la cultura avaloran todos los logros por igual, y los consideran en tanto manifestación del espíritu y de su creación en libertad. K. Vossler proclamaba en concreto: «La historia de la evolución de la lengua no puede ser otra que la historia de las formas de la expresión espiritual [...]. La Historia del Estilo y de la Literatura [...] forma parte de la Historia del espíritu y libertad humanos» (Vossler, 1929, p. 19), y esta proclama ha resonado mucho luego en otros autores, por ej. en el libro del eminente Eugenio Coseriu Sincronía, Diacronía e Historia.

El lenguaje (se entiende que lo mismo el ordinario que el literario) resulta así una creación del espíritu, y de esta manera y aplicado a la obra de arte verbal, la estética crítica «compara - mantiene Vossler - la obra de arte con ella misma, porque ha comprendido que los ideales de belleza son tantos cuantas obras de arte»: la libertad del espíritu da lugar a una elocución que ha de avalorarse por sí misma, y que la estética crítica considerará lograda o no, para lo cual el crítico ha de reproducir conscientemente «el proceso interno que ha conducido a la obra de arte», idea esta última que hará suya Amado Alonso aunque no la 
remita al maestro germano. En definitiva — mantiene por igual el romanista de Múnich-, la crítica estética del idioma en tanto creación, pertenece igualmente a la historia de la literatura y a la ciencia del lenguaje (Vossler, 1929, pp. 44, 49, y 193).

Si los ideales de belleza son tantos como las obras logradas de arte verbal, entonces se han de valorar tales obras en tanto «ensayos de resolución de problemas estéticos efectivamente planteados», dirá con agudeza el romanista unos años más tarde (Vossler, 1963, p. 50); se trata en verdad de problemas estéticos que se resuelven en un discurso elocutivo que procede de la libertad del espíritu del emisor del mensaje.

Y tal discurso artístico-elocutivo resulta ser un objeto avalorable por sí mismo según su retórica, según su invención, disposición, y elocución (componente al que atendemos sobre todo ahora): la esteticidad deriva de esa retórica —usada la voz en su sentido más clásico y noble-, y deriva muy en lo fundamental de la elocución, del espesor elocutivo.

La esteticidad del objeto de arte verbal quedó enunciada por los mismos años de Vossler por el formalista ruso Víktor Sklovskij, quien enunció de manera muy lúcida:

Nosotros llamaremos objetos estéticos [...] a los objetos creados mediante procedimientos particulares, cuya finalidad es la de asegurar para estos objetos una percepción estética. [...] La automatización devora los objetos, los hábitos, los muebles, la mujer y el miedo a la guerra. [...] Para dar sensación de vida, para sentir los objetos, para percibir que la piedra es piedra, existe eso que se llama arte. La finalidad del arte es dar una sensación del objeto como visión y no como reconocimiento: los procedimientos del arte son el de la singularización de los objetos, y el que consiste en oscurecer la forma, en aumentar la dificultad y la duración de la percepción. El acto de percepción es en arte un fin en sí y debe ser prolongado. El arte es un medio de experimentar el devenir del objeto: lo que ya está «realizado» no interesa para el arte. (Sklovskij, 1917 , pp. 57 y 60)

El espesor elocutivo resulta un factor fundamental creador de esteticidad, y cabe decirlo de manera difícilmente más plástica que como lo hace el autor ruso. Estamos ante la enunciación de una teoría estética que es la que siguieron los grandes creadores de estilo, como todos los autores de gran logro elocutivo, desde Juan Ruiz a Góngora o Valle-Inclán, Azorín, García Lorca...

Un objeto pasa trivialmente inadvertido, pero el arte lo hace nacer para nuestra percepción si esa percepción resulta analítica y consciente: el arte es artificio y requiere una percepción según tal artificio.

La historia de los estilos consiste en la historia de los estilos de la lengua y del habla, que responden a gustos del hablar bien común bien literario, y que responden por tanto - sobre todo los segundos- a una esteticidad que en general dificultan la percepción y llaman la atención sobre sí mismos: es la llamada con Jakobson función poética del lenguaje. Según vamos a ver, la historia de varios de los estilos españoles es la historia de elocuciones planteadas y resueltas en tanto hechos estéticos: cultismo latinizante en el Cuatrocientos, claridad expresiva en el Quinientos, más tarde el Barroco que se opone a ese Quinientos... 


\subsection{Estilística y percepción artística}

De manera personal o a veces en la traza de Vossler, don Ramón Menéndez Pidal llevó a cabo enunciados que convergen con los de este autor de Múnich o con los de los formalistas rusos, desconocidos cuando escribía las páginas que vamos a ver de don Ramón (años treinta y primeros cuarenta) el maestro nacido en La Coruña.

Menéndez Pidal se remite de manera expresa a Vossler cuando en efecto manifiesta que «los ideales —en la obra artística— son tantos cuantas son las obras de arte» (Menéndez Pidal, 2005, II, p. 10): el autor analizará así varios de los estilos literarios de la serie castellana, de la literatura española, cuando traza la diacronía de la lengua, y hace estimación de que asimismo lo lleve a cabo Rafael Lapesa en su propia Historia del idioma (también rotulada Historia de la lengua española).

Y el propio don Ramón, no mucho antes de escribir esas líneas, tenía estampadas otras en la que establecía —en convergencia con los formalistas rusos - que la evolución de la lengua poética obedece a cambios que vienen determinados por el embotamiento de la percepción y la necesidad estética de renovarla, de activarla. Dice ciertamente Menéndez Pidal acerca de la evolución linguiístico-artística, en párrafo que pocas veces se ha advertido, cómo tal evolución

va condicionada por un factor psicológico constante, y es la necesidad de reparar un instrumento que se usa todos los instantes del día y que se embota con el uso, la necesidad de aguzar a menudo el filo de la palabra, renovándola para el acto de grabar sobre la distracción y el cansancio del oyente.Y tal renovar suele moverse entre dos extremos: ora espontaneidad, sencillez, llaneza; ora artificio, complicación, reconditez. Gran parte de la historia de la lengua literaria se explica por ese vaivén: a una época en que la expresión artística aspira a iluminar el espíritu con blanca claridad, sucede otra que opera sobre el relajamiento de la atención, esforzando las coloraciones o buscando penumbras y hasta oscuridad; acciones y reacciones, movimiento pendular, aunque no ciertamente simple, sino turbado por impulsos varios. (Menéndez Pidal, 1933, pp. 17-18)

Cuando nuestro autor se plantea hacer una historia evolutiva de la lengua española común y de su idioma artístico, de la sucesión de los estilos elocutivos, percibe bien que la sucesión de los estilos artísticos viene determinada por el agotamiento perceptivo, por lo que sobre todo en Historia del Arte se denomina el cansancio de las formas; no obstante don Ramón opone sencillez a artificio, lo que no resulta exactamente así, pues toda elocución literaria conseguida y lograda lleva en ella algún grado de artificio. En la historia de los estilos del arte verbal se suceden más bien la claridad y la oscuridad, la sencillez y la complicación: quizá en Pidal actuaba el contraste establecido años antes por Heinrich Woelfflin -y pasado al castellano por José Moreno Villa_, entre lo lineal y lo pictórico; la forma cerrada y la forma abierta; «la claridad absoluta y la claridad relativa de los objetos»; etc. Al Renacimiento sucede de esta manera el Barroco, y Pidal opera con esta idea de la sucesión de los estilos cuando ha escrito amplias páginas en torno a nuestras centurias del XVI y del XVII; de hecho ya en el artículo sobre el idioma del Quinientos exclamaba que —al trazar una periodización-, «aun a menudo la centena suele parecer poco, y se habla de los si- 
glos XVI y XVII mezcladamente - los siglos de oro-, confundiendo las direcciones del uno con las del otro (1933, p. 9); el autor practicaba un muy adecuado positivismo analítico, y de ahí su afán en discriminar épocas distintas: el idioma artístico se prestaba más desde luego a la periodización precisa, al sucederse de los estilos, aunque no obstante don Ramón formulaba una especie de hipótesis acerca de una cierta unicidad entre la cronología de los estilos de arte verbal y la lengua común colectiva; tras exponer el autor cómo «los fenómenos lingüísticos de carácter colectivo carecen en su mayor parte de una cronología precisa debido a su proceso largo y anónimo», mientras la estilística personal permite la periodización mejor definida, expone ciertamente:

Atiendo [... en mi Historia de la lengua española (2005)] a las principales corrientes de la estilística personal, única que tiene una documentación precisa, suministrada por las obras de los autores. [...] Es de presumir además que las tendencias de la estilística personal, que opera sobre los elementos del lenguaje tocantes a la creación individual del habla, tengan alguna correlación con las de la estilística colectiva, que opera sobre los elementos tradicionales del lenguaje. (Menéndez Pidal, 2005, II, pp. 73-75)

Estamos por tanto ante un muy sugestivo programa de investigación: el de tratar de establecer cadencias coincidentes entre la estilística literaria lograda en una lengua y la estilística colectiva de esa misma lengua.

Ha dicho asimismo el propio Menéndez Pidal que el habla literaria, «como acto artístico perdurable, $\mathrm{t}$ [iende] a una expresión que sirva para todos y para siempre» (2005, II, p. 21), o sea, que el mensaje literario ha de conservarse en sus propios términos y sin delimitación temporal (perdurable), y va dirigido a todos (a un receptor universal).

En las presentes páginas de su Historia de la lengua española —redactadas hacia final de los años treinta e inicio de los cuarenta-, el autor retoma la idea de cómo el embotamiento de la percepción lleva al cansancio de los estilos y a su renovación. Argumenta de esta manera el maestro:

1. Se dan dos móviles psicológicos de la innovación, a saber: «la mayor eficiencia del lenguaje sobre el oyente», y el «impulso del escritor para [...] desahogar la interioridad y acaso también necesidad de singularizarse, colocarse aparte del común hablar».2. Existen «dos tipos estilísticos principales»: «un estilo de naturalidad» y otro «estilo de artificiosidad», los cuales prefieren respectivamente la «selección» en el idioma o la «invención». (2005, II, pp. 63-69)

Se trata en lo principal de la claridad estilística frente a la oscuridad o dificultad, y de que junto al cansancio de las formas actúa por igual el afán innovador de originalidad: se trata de escribir contra, de afirmar la originalidad artística a diferencia de como escriben los otros autores; toda creación de uno u otro estilo es escribir contra. 


\subsection{Las artes en las fases A y B de lo histórico}

Queda visto cómo por parte de la historiografía del arte (Woelfflin) y del lado de los filólogos (Menéndez Pidal), se han establecido períodos cíclicos que se suceden en la historia de los estilos artísticos; ha de saberse también que la historiografía general ha hablado de las fases A y B de lo histórico, que se dan en la historia económica y social, y asimismo en el devenir de la cultura y por tanto en el arte, etc.

La mejor exposición que se ha hecho entre nosotros de estas cuestiones es la de Joan Reglà, primero en lengua catalana y enseguida y en versión definitiva — con algún recorte y ligeras adiciones - en castellano: lo hizo en su Introducción a la historia (1970).

Este libro que mencionamos es una bella obra que creemos constituye (junto a la Teoría del saber histórico de José Antonio Maravall; con posterioridad hay un texto en parte semejante de Julio Aróstegui, y otros más) lo mejor que se hizo en su momento en su género y en nuestra literatura técnica. Reglá va recapitulando:

a) «Hay los movimientos cíclicos, los cambios coyunturales, que representan las fluctuaciones digamos positiva y negativa, expansión y depresión o recesión [...]. Son respectivamente las fases A y B, según la terminología de François Simiand. [...] De fines del XV a comienzos del XVI se verifica el cambio de coyuntura, y en el transcurso del Quinientos, la fuerte expansión - fase A- que dura hasta 16051630. Entonces se inicia una nueva fase de recesión - B - que preside en todo el Occidente europeo, la «decadencia» del siglo XVII».

b) Las fases A o de expansión se manifiestan en la cultura por la libertad y el clasicismo, y las fases B de depresión por la cultura dirigida, el Barroco de evasión y las introspecciones.

c) «En el siglo XVI la expansión y el absolutismo de tipo patriarcal de los Habsburgo coinciden con el clasicismo; la depresión del siglo XVII, [...] y la culminación del absolutismo monárquico [...], con el barroquismo; y la recesión de la primera mitad del siglo XIX, con el romanticismo y el conservadurismo del «sistema Metternich» (Reglá, 1970, pp. 30-31; 37-38; 46-47 ; y vid. además 90-92).

Desde luego lo histórico nunca es mecánico ni se halla completamente determinado, y esto son sólo tendencias generales que subyacen a una manifestación mucho más compleja y matizada de la realidad. De esta manera el mismo autor llama la atención a lo que ocurre en el primer tercio del siglo xx, en que la expansión y el crecimiento más el imperio de la técnica que favorecen las desigualdades, «facilitan la crisis social, política, ideológica y espiritual. [...Entonces resulta ] evidente que los propietarios rurales y la burguesía industrial se aferran a un conservadurismo social al que las organizaciones obreras oponen la acción directa y la violencia»; desde el punto de vista de los estilos, podemos apuntar por nuestra cuenta que en el primer tercio del xx se producen rasgos de estilo artístico de las fases B, es decir, estamos ante un academicismo vanguardista, también ante la vanguardia de evasión en algunos autores — de ahí que se postulase por varios escritores un «nuevo romanticismo», lo que supuso por igual un estado de introspección-; según apunta Reglà y pese 
a hallarnos en una fase A expansiva, encontramos no obstante «introspecciones [...] con las respuestas a la crisis de 1898 y [...] la problemática suscitada por la guerra civil de 1936».

De hecho la presente exposición teórica del profesor gerundense J. Reglà subyacía ya al volumen colectivo que hizo con sus entonces colegas valencianos Antonio Ubieto y José María Jover Introducción a la Historia de España (1963); en esta obra escribió por ej. nuestro autor respecto a la estilística barroca: «La cultura nacional acusa de manera inmediata el impacto de la crisis que afecta contemporáneamente a distintos planos de la vida española: desde la economía hasta la articulación política. Sobre un común denominador barroco, se manifiestan en la literatura de la época dos tendencias — culteranismo y conceptismo - en las cuales [se] ha visto respectivamente una tentativa de enmascarar retóricamente la dificultad de los tiempos, y un repliegue ascético — no exento de pesimismo - en busca de lo esencial» (Reglá, 1963, p. 322).

Y de manera muy expresa caracteriza aún, tempranamente respecto de otros estudiosos:

Popular y conservador, el Barroco sustituye la especulación renacentista por la acción, la práctica y el empirismo; mientras el clasicismo se interesaba por los círculos restringidos de intelectuales, el Barroco (con las guerras de religión) se dirige a las multitudes, hablándoles el lenguaje claro de los sentidos, para reconquistarlas o retenerlas en el seno de la Iglesia. [...] La evasión colectiva tuvo [...] sus espectáculos de masas: las ceremonias religiosas en los templos, a las que el Barroco añadió un nuevo elemento, el púlpito; y las representaciones teatrales, convertidas en verdadero espectáculo nacional. (Ibid., pp. 320-321; vid. la presente exposición de Reglá, que incluye naturalmente las revoluciones de Cataluña y Portugal, etc., más bibliografía en p. 344)

Nuestro historiador insistió siempre en la interacción en el desarrollo histórico de los planos o niveles de las actividades humanas - socioeconomía, política, cultura y relaciones exteriores-, y así puede escribir párrafos como el que acabamos de transcribir; también sus compañeros de esa Introducción a la Historia de España analizaron en unas u otras páginas propias la posible interdependencia entre la cultura y las artes por una parte, y los demás componentes de lo histórico por otra.

Pero debe decirse que en el tratamiento extenso y desconocido en conjunto hasta hace poco hecho por Menéndez Pidal del Quinientos y el Seiscientos literarios, en ese tratamiento (decimos), se alude de manera inequívoca por igual $-\mathrm{y}$ aunque sea de manera más intuitiva - a las fases A y B de lo histórico, aunque sin llamarlas así: el Seiscientos resulta la fase B que sucede y contrasta con la fase A de la centuria anterior.

De esta manera habla por ej. don Ramón cuando trata de la literatura barroca, de «una reacción contra el clasicismo renacentista, promovida no sólo en literatura sino en las demás artes y en el espíritu general de la época»; en la misma orientación alude el autor a los denominados culteranismo y conceptismo, y entiende tales dos corrientes en tanto «reacción que son las dos contra el siglo XVI», de manera que «coinciden en varios procedimientos, pues participan [...] de la misma reacción» (Menéndez Pidal, 2005, I, pp. 1137 y 1253 1254; volveremos a verlo). 


\section{4. «Renacimiento»}

El Renacimiento del XVI español, entendido en tanto 'movimiento cultural y artístico' y en general el Renacimiento, estaba ya caracterizado en los manuales tradicionales de manera aceptable: por ej. en uno de Ciriaco Pérez-Bustamante, leíamos: «A través de los antiguos se vuelve a la Naturaleza, se emancipa el individuo de los prejuicios y se desarrollan el espíritu de invención, la observación directa de los fenómenos y el conocimiento científico, la exaltación de la personalidad, el individualismo, el afán de gloria y de fama». Un tratado de mucho relieve fue el de Delumeau La civilización del Renacimiento, quien planteó entre otras muchas cosas:

a) Respecto a la palabra. «¿Con qué otro vocablo [que el de Renacimiento] señalar esa gran evolución que condujo a nuestros antepasados hacia una mayor ciencia, más conocimientos, más dominio de la naturaleza, más amor por la belleza?».

b) Tal voz «Renacimiento», en el marco de una Historia total, «significa y sólo puede significar la promoción de Occidente en la época en que la civilización de Europa se distancia de manera decisiva de las civilizaciones paralelas». Se trató de la ascensión del Occidente hasta hacerse una civilización considerada superior.

c) «El término de «Renacimiento», inexacto por más de una razón [no hubo una ruptura histórica tajante, etc.], es no obstante para el historiador, testimonio de la conciencia que una época tuvo de sí misma».

d) El carácter que define lo renacentista es el de «inspirarse en los antiguos para la ejecución de lo nuevo»; se trata realmente por tanto de una superación de los antiguos, de la primacía de los modernos sobre los antiguos.

e) «Miguel Ángel optó por el movimiento y lo sobrehumano, [por...] la desmesura. Fue así uno de los creadores del arte barroco». Entre nosotros Emilio Orozco analizó asimismo el barroquismo de Miguel Ángel (Delumeau, 1977, p. 18; 102; 138; 141).

¿Y qué cabe decir de la voz $r(R)$ enacimiento en la lengua castellana?. La palabra se halla ya presente en el primer Diccionario Académico, el conocido como «de Autoridades», y entonces posee la acepción (1737) de 'el acto de renacer', y tal significado se mantiene en todas las sucesivas ediciones del DRAE desde 1780 hasta 1843; será más a mitad del Ochocientos, en la edición de 1852 del diccionario oficial, cuando aparezca una leve innovación, la de añadir a 'el acto de renacer' esto: «y así se dice: el RENACIMIENTO [...] de las artes».

El DRAE de 1869 repite al anterior del año 52, mas el de cuidada factura de 1884 introduce una novedad capital, y que llega hasta nuestros días en las sucesivas ediciones de este léxico: la palabra significa en este año 84 'acción de renacer', y además: 'época que comienza á mediados del siglo xv, en que se despertó en Occidente vivo entusiasmo por el estudio de la antigüedad clásica griega y latina'; según decimos, los trece léxicos académicos aparecidos con posterioridad —incluimos en el recuento el Diccionario común más el Manual— repiten la redacción de la entrada que ya apareció en ese buen DRAE de 1884 .

La lexicografía no académica, en su competencia en el mercado con la académica, incorporó antes la acepción que nos importa, y de esta manera el Diccionario de la casa Gas- 
par y Roig de 1855 definía un tanto enciclopédicamente: 'nombre conque se designa la época de la resurreccion de las letras y las artes que desaparecieron con la caida del Imperio Romano y de Carlomagno. Durante aquel olvido, los que permanecieron fieles al culto de las bellas artes no hallaron refujio contra la barbarie sino en la antigua Bizancio. Arrojados por el sable de Mahomet II que sometió el Imperio Griego en 1453, los artistas se refujiaron en Italia, y Lorenzo de Médicis, el Magnífico, los tomó bajo su proteccion'.

Cuarenta años más tarde de este léxico del que acabamos de consignar la acepción histórica de Renacimiento, el otro Diccionario de Zerolo (1895) redacta una acepción más enciclopédica y de mayores concreciones: 'Epoca que comienza á mediados del siglo XV, en que se despertó en Occidente vivo entusiasmo por el estudio de la antigüedad clásica griega y latina. Esta época se halla comprendida entre el año 1453 y la segunda mitad del siglo XVI. El renacimiento, modo abreviado de expresar la idea «resurrección de las artes y las letras», fué comenzado por los sabios y artistas bizantinos, continuadores de las tradiciones de la antigüedad griega, que, después de la conquista de Constantinopla por Mahomet II, emigraron á Italia y luego á Francia. El renacimiento fué como la aurora de los tiempos modernos y brillo en todo su apogeo en Italia bajo los Médicis y en Francia bajo el reinado de Francisco I'.

El presente Diccionario toma a la letra palabras del $D R A E$, seguramente ha tenido asimismo a la vista el de Gaspar y Roig, y ha añadido algún complemento erudito.

\section{II}

\subsection{Conceptismo, gongorismo}

Juan Luis Alborg, en sus «urgentes generalizaciones» al respecto, caracteriza al Barroco en tanto un arte de excelencias formales,

un arte acumulativo, que pretende impresionar los sentidos y la imaginación con estímulos poderosos, fuera de lo común. Estos estímulos pueden dirigirse al entendimiento $-y$ se manifiestan en retorcidas agudezas, imágenes brillantes, ideas ingeniosas y todo género de novedades y audacias estilísticas, que constituyen lo que tradicionalmente se viene denominando cultismo y conceptismo-o pueden apuntar hacia el sentimiento, y entonces se valen de todos los medios capaces de excitar el terror o la compasión, provocar la admiración o la sorpresa, sirviéndose de temas maravillosos, pintorescos, grotescos o monstruosos. (Alborg, 1970b, p. 13)

Si de acuerdo con el conocido pasaje de Gracián el concepto supone el establecimiento de una correspondencia entre los objetos, Góngora resulta evidentemente conceptuoso: esto se ha interpretado así por sucesivos críticos, uno de los cuales ha sido Alexander A. Parker (1952).

Este relevante hispanista - Parker - interpretó que el conceptismo es «el fenómeno primario» en el estilo literario barroco, y consecuentemente — así- la idea y la voz culteranismo denotan la latinización del lenguaje (cultismos, hipérbatos...) más «el empleo de 
las metáforas genéricas típicamente gongorinas (nieve, oro, cristal, etc.)», metáforas que se basan «en conceptos implícitos». Un cuarto de siglo más tarde el mismo Parker advertía cómo agudeza es «la agilidad intelectual que permite ver las similitudes en cosas aparentemente disímiles al descubrir «correspondencias» que no son evidentes por sí mismas» ( apud Luis de Góngora, 1996, p. 31). En el presente hilo de argumentación ha de tenerse presente el tratamiento de F. Lázaro, quien viene a coincidir con Parker y el cual sintetiza algunas ideas. En tal síntesis este autor interpreta en torno a la lengua literaria del XVII un par de hechos:

1. «[En el siglo XVII] los artistas aprovechan aprovechan al máximo las posibilidades sensoriales del material que emplean, y los escritores no escapan a esta tendencia. Efectivamente la lengua literaria del período barroco se caracteriza en general por los alardes verbales. [...] Un nuevo ideal idiomático se impone y triunfa, cuyos más grandes artífices serán Góngora y Quevedo. El lenguaje es primordialmente para ellos signo de sí mismo [...]. El lenguaje es el principal protagonista de las obras» de ese estilo barroco. Aunque el crítico matiza la rotundidad esta última aserción, la verdad es que los autores del Barroco — podemos decir_ - vehiculan también en sus textos unas sustancias de contenido, por lo que sería más adecuado mantener que en las obras del XVII el lenguaje es signo de sí mismo, más en variable proporción - mayor de la que concede Lázaro - signo referencial, es decir, signo de unos referidos denotados/connotados: Góngora se suma por ej. a la condena de las navegaciones en tanto signo de codicia que se hallaba en la mentalidad del momento; nada digamos de las moralidades de Quevedo o del autobiografismo lírico de Lope.

2. Culteranismo y conceptismo resultan soluciones distintas al mismo problema de conseguir efectos artísticos a partir primordialmente de lo lingüístico. «Conceptistas y culteranos fueron igualmente ingeniosos, es decir, combinadores, y contaron como instrumento para exhibir su ingenio con el concepto». La correspondencia que se halla entre los objetos o «concepto» la plasmaron mediante comparaciones, alegorías, antítesis, paronomasias, calambures, dobles significados, metáforas...

Ciertamente culteranismo y conceptismo «poseen una base común: la forja de conceptos» (Lázaro, 1971, pp. 186 y ss.).

Hay una perspectiva que revela complejidades olvidadas en ocasiones, y es la de Maxime Chevalier, quien ha ejemplificado cómo la agudeza verbal gozó de gran aceptación en los siglos XVI y XVII, y así se dio una literatura aguda a la que pertenece parte de la obra quevedesca; de hecho ya el hispanista Ludwig Pfandl había postulado en su día cómo «el conceptismo era más bien [entonces] un estado latente» (1952, p. 275). El otro hispanista M. Chevalier anota por ej. la pasión por la agudeza en los primeros años del Seiscientos, y en cuanto a Quevedo escribe:

La obra quevediana no surge de la nada. Quevedo aprovecha la literatura jocosa (o aguda) del siglo xvi [...Quevedo comparte con sus antecesores y coetáneos] la convicción de que la virtud y superioridad de la lengua española consiste en la rica cantera de juegos verbales que encierra; concluye que la lengua española se basta a sí misma. (Chevalier, 1992, pp. 9, 109-110, y 113-114) 
La idea de la lengua castellana de don Francisco es pues la de su avaloración, sin necesidad de acudir al latinismo (cfr. además la Historia pidalina, pp. 1200-1203; ahora M. Blanco, quien ha escrito Les Rhétoriques de la Pointe. Baltasar Gracián et le Conceptisme en Europe, quizá esp. pp. 60 y ss.; el cap. VII (pp. 245-314); etc. La misma autora acaba de sacar dos volúmenes — con materiales antiguos y nuevos- en torno a Góngora y que tratan de Góngora y el concepto).

\subsection{Las dos épocas y la lengua poética de don Luis}

De manera solamente intuitiva, Menéndez Pidal percibe bien que en el XVI y el XVII se dan respectivamente una fase A y otra B, y así se expresa: «La causa [...] del nuevo estilo [del XVII...] no es otra sino la intensa necesidad de reacción contra el clasicismo renacentista, promovida no sólo en literatura sino en las demás artes»; se opondrá así un «arte de oscuridad o dificultad» a un anterior «arte de claridad» (Menéndez Pidal, 2005, I, pp. 11361137).

El propio don Ramón tiene un párrafo afortunado acerca de las cuestiones que plantea la trayectoria poética de Góngora, y que dice:

La vida poética de Góngora nos ofrece a través de todo su curso longitudinal la división que se da en todos los poetas de entonces: de una parte las obras de entonación más docta, canciones, poemas, sonetos y demás poesías en metros renacentistas, y de otra parte las de tono más sencillo, letrillas, romances, y demás composiciones en metros cortos; pero además nos presenta una división vertical o cronológica observable especialmente en las obras de metro renacentista: desde 1580 hasta hacia 1610, Góngora escribe esas obras dentro de los límites estilísticos comunes a los demás poetas de su tiempo; después se aparta de ellos notablemente. (Para lo relativo a don Luis, Menéndez Pidal, 2005, I, pp. 1144-1197)

El presente párrafo no ha sido conocido hasta hace poco, pero la idea sí la difundió Pidal en el artículo «Obscuridad, dificultad entre culteranos y conceptistas», al dar término a esas páginas postulando «cómo hallándose todos los elementos del gongorismo en las épocas anteriores, con ellos se constituye una modalidad de arte completamente nueva, mediante la acumulación de ellos y la general intensificación de la artificiosidad» (1966, p. 230).

Dámaso Alonso sabido es que postuló una división longitud y no transversal en la obra poética gongorina, y pedía así que se admitan dos maneras consustanciales al escritor que le acompañan a lo largo de toda su vida literaria, pues «la división cronológica no existe» (D. Alonso, 1978, pp. 7-238: pp. 13-48); más ajustado a los hechos nos parece don Ramón, quien advierte la diferenciación cualitativa que se da en el tejido lingüístico-discursivo a partir efectivamente de hacia 1610.

Menéndez Pidal subraya especialmente su interpretación al manifestar que aunque Góngora en el Polifemo y las Soledades y en el Panegírico al Duque de Lerma «no cambia de procedimientos estilísticos radicalmente, cambia realmente de estilo».Coincidirá con la postura interpretativa pidalina y se sumará a ella F. Lázaro, quien escribe entre otras cosas: 
«La «segunda manera» [...del poeta] resultaría de la seguridad que Góngora va adquiriendo en la eficacia estética de sus hallazgos e invenciones. Tanto los temas como los procedimientos expresivos ya existentes en su poesía anterior se someten a un tratamiento mucho más consciente e intenso» (1984, pp. 60-61).

El maestro Menéndez Pidal, que ya conocía cuando escribió el volumen mencionado de D. Alonso «La lengua poética de Góngora», tiene en cuenta algunas singularidades de don Luis en el uso del idioma que por pura lógica ya había tenido en cuenta su discípulo, y además insiste en algunos hechos. Por ej. se extiende acerca de cómo la perífrasis sustituye el nombre: «Mientras Garcilaso empleaba poco la perífrasis, pues gustaba los términos «no desusados de la gente», ahora Góngora evita a cada instante, casi por sistema, el nombre común, sustituyéndolo por un rodeo en que se menciona algún carácter o cualidad del objeto, algún recuerdo mitológico, histórico o de cualquier clase que sustituya con ventaja al nombre omitido». En efecto Garcilaso tenía el propósito de expresarse de acuerdo con un idioma común, que tendiese a lo permanente, y ahora Góngora elige —en la trayectoria de la serie literaria- otra manera de expresividad que es la de la elusión cifrada artísticamente.

Pidal insiste en que ciertamente «Góngora hace del latinismo un procedimiento habitual de poetización, y lo utiliza no para suplir faltas de la lengua común, sino para expulsar de la lengua poética el vocablo común, porque se sienta el principio de que en el lenguaje culto no se han de nombrar las cosas por su nombre ordinario»: en referencia a Garcilaso estamos ante dos poéticas, la del empleo de los términos «no desusados de la gente», y la de que en el lenguaje culto no se han de designar las cosas por su nombre ordinario.

Al sentido estético de la lengua gongorina se refirió Emilio Orozco, quien apunta cómo en los primeros tiempos modernos se inicia un movimiento cultista, y así ocurre que

el deseo de dignificar la lengua romance, que ya lo sintió Juan de Mena, es algo general en el Renacimiento; y para ello los ojos se vuelven hacia el latín. En general piensan que el romance es un latín corrompido, y en consecuencia se piensa restaurar la lengua ante los modelos de los escritores de Roma. El estudio de la lengua romance atrae a los humanistas y poetas, que en forma creciente la defienden y proclaman apta para la expresión de lo más noble, grave y trascendente. Para ello se hace preciso aumentar su poder de expresión introduciendo palabras griegas, latinas o italianas, y estudiarla y escribirla [...]. Porque el criterio de naturalidad [...] cada vez satisface menos al poeta, incluso al clásico Fray Luis de León.

Y ocurre en el caso de don Luis de Góngora que vino a dar «plena realización» al aludido designio cultista de los modernos, incurriendo incluso — barrocamente - en la oscuridad; se elevaba así la dignidad del romance, del vulgar sobre el latín, y se daba lugar a una lengua poética de amplias posibilidades expresivas (Orozco, 1953, pp. 130-134).

En su línea de interpretación formalista, F. Lázaro piensa que don Luis «está sentimentalmente distante de los temas, y la única emoción que en él se percibe es la del creador lingüístico, la del artista de la palabra, que plasma en fórmulas «ingeniosas», deslumbrantes o atrevidas, los contenidos que le sirven de pretexto para crear» (1971, las pp. ya 
aludidas 190-191); no creemos nosotros que sea enteramente así, pues en la obra de Góngora no falta el pensamiento — otra cosa es que no se alcance a percibir- : la temática de un gran autor no resulta nunca sin más un «pretexto»: ningún gran autor se halla vacío de sustancias de contenido, de significaciones que precipitan en un sentido último del texto; idiomáticamente el «sentido» es eso, el precipitado final de las significaciones acumuladas en un texto.

En particular en la lengua poética de Góngora analiza don Dámaso en primer lugar los cultismos, y llega a dos conclusiones que se han difundido en manuales y exposiciones de conjunto:

a) «Lo único que hizo Góngora fue popularizar, difundir, una serie de vocablos de los cuales la mayor parte eran ya usados en literatura y habían conseguido entrada en los vocabularios de la época, y sólo los menos —en realidad una minoría reducidísima - podían ser considerados como raros [...] La portentosa difusión y permanencia del gongorismo (que dura hasta bien entrado el siglo XVIII) colaboró en primera línea en la fijación en la literatura (y de la literatura pasaron al lenguaje hablado) de una parte importante de los vocablos que hoy forman nuestro idioma». O sea - y este párrafo resulta de interés para la historia de la lengua (literaria) española:

El léxico de Góngora llena el vacío de originalidad de la mayor parte de los escritores del siglo xvii, y ni aun los verdaderamente originales se ven libres de él, más aún, se propaga hasta los más encarnizados enemigos del poeta, inunda la prosa, triunfa en la cátedra sagrada: de este modo la lengua literaria del xvii se sobresatura de cultismos, y cuando se retiran las aguas, cuando en el siglo xviii cambia el gusto, el milagro está ya hecho: la lengua vulgar ha sufrido las infiltraciones del torrente erudito, y las palabras que escandalizaban a un Quevedo, han adquirido ya carta innegable de ciudadanía castellana».

b) «Lo que irritaba [...] era el abuso de la repetición sistemática de las mismas voces cultistas y su agrupamiento dentro de un poema. Sólo merced a la repetición y al agrupamiento de latinismos (y no a la extravagancia de éstos) pudo parecer cultista el léxico de una obra como las Soledades» (1978, pp. 49-128). El razonamiento del crítico parece sensato: don Luis recoge, enriquece y propaga el léxico cultista patrimonial, aunque la dificultad acumulada en su lírica — sintáctica, léxica, de las figuras - llevaba a rechazar o minusvalorar sus versos, en cuanto llevaba a su vez a un grado de oscuridad.

Analiza también Dámaso Alonso en nuestro poeta la existencia de fórmulas estilísticas repetidas, aunque tal análisis cabe ampliarlo; en todo caso encontramos en don Luis formas de construcción sintáctica como estas: no de A, sino de $B$ («no de oro / ciñe, sino de púrpura, turbante»); $A$, ya que nо $B$ («Tú, ave peregrina, / arrogante esplendor - ya que no bello— / del último Occidente»); A no, B sí («clavo no, espuela sí del apetito»); en A no, en $B$ («en plantas no escrita, / en piedras sí»); etc. (1978, pp. 144-167, con algún ejemplo que añadimos). 
Pueden registrarse además varios cultismos sintácticos gongorinos:

—El verbo «ser» en un significado de 'servir', etc., con un sujeto, un sustantivo predicado y un dativo («el melancólico vacío / a Polifemo [...] / bárbara choza es»).

- Acusativo griego («lasciva el movimiento / mas los ojos honesta»).

— Ablativos absolutos («el sueño de sus miembros sacudido / gallardo el joven la persona ostenta»).

Según nuestro crítico, el poeta se aficiona a aquellas expresiones de su estilo que más se separaban de lo vulgar, y las repite y apura (Ibid., 168-187).

Otro recurso gongorino es el del hipérbaton, en búsqueda también de un efecto estético: «cuantos pisan faunos la montaña»; «tanta ofrecen los álamos zagala»; ... (Ibid., pp. 188-226).

Recordemos que don José Manuel Blecua entendió alguna vez que así como el afán cultista de Góngora le llevó a las Soledades, su ambición conceptista le llevaría a la Fábula de Píramo y Tisbe, con la que quiso demostrar que era además un muy agudo conceptista (Blecua, 1977).

En fin dígase que se ha observado que las artes o poéticas tradicional y de cancionero, e italianizante, conviven en el Barroco: romancero nuevo, estribillos glosados, lírica jocosa, etc.

\subsection{Los comentaristas: «Restituya Vm. a su casa la claridad»}

A lo largo de las décadas primeras del siglo XVII irán apareciendo los textos de la poética cultista y gongorina, así como los textos de la polémica de las «Soledades». Aquí vamos a hacer algunas ilustraciones acerca de varios de tales escritos representativos por lo que tienen que ver con la elocución; nos referiremos a los pasos iniciales de la polémica, los de 1613-1614, según una interpretación personal de cada texto.

Veremos así los escritos siguientes:

1. 30 de junio de 1613: Pedro de Valencia.

2. Verano de 1613 (M.J. Osuna): «Advertencias» de Andrés de Almansa y Mendoza.

3. La dama boba de Lope.

4. 13 de septiembre de 1613: «Carta de un amigo de D. Luis de Góngora» (¿algún amigo de Lope?).

5. 30 de septiembre de 1613: carta de D. Luis de Góngora «en respuesta de la que le escribieron».

6. 16 de enero de 1614: carta ¿de Lope?

7. Principios de 1614: Abad de Rute. 
1. Cuando escribía el Polifemo y las Soledades, Góngora pidió opinión y consejo sobre ese modo de nueva poesía suya al humanista Pedro de Valencia antes, y luego a don Francisco Fernández de Córdoba, Abad de Rute.

El primero de ellos le contestó el 30 de junio de 1613, y le advertía:

Huye la claridad, y escurécese tanto, que espanta de su leción no solamente al vulgo profano, sino a los que más presumen de sabidos en su aldea. También, por estrañar i hazer más levantado el estilo, usa trasponer los vocablos a lugares que no sufre la phrasis ['habla'] de la lengua castellana [...]. También, siguiendo esta novedad, usa de vocablos peregrinos Italianos i otros del todo Latinos [...]. Estos conviene moderar i usar pocas veces. (Manuel M. Pérez, 1988, p. 76)

Nuestro humanista censura varios aspectos del alto estilo de don Luis: el que huya la claridad y se haga oscuro, en el orden de palabras los hipérbatos, el neologismo, ... Antes le ha dicho que espanta de su lectura, y por el presente y otros lugares ve Menéndez Pidal el extraordinario hermetismo a que había llegado la nueva lírica: hermética aun para personalidad tan erudita e instruida como Pedro de Valencia. Resultaba hermética — dice a la letra don Ramón — «aun para personas más instruídas que Góngora en las literaturas clásicas, donde la poesía romance de aquellos siglos tomaba a manos llenas sus metáforas y alusiones. Lo era igualmente para los poetas más ejercitados y más a la moda de entonces» (Menéndez Pidal, 1966, p. 220).

Por igual le señala el humanista a Góngora los que asimismo estima vicios:

Lo metaphórico es generalmente mui bueno en v. m., algunas veces atrevido i que no guarda la analogía i correspondencia que se requiere; otras se funda en allusiones burlescas $i$ que no convienen a este estilo alto i materias graves [...]. En estos vicios digo que cae v. m. de propósito i haziéndose fuerça, por estrañarse i imitar a los Italianos $i$ a los modernos affectados, que se affectan o afeitan por falta de ingenio i hermosura propia; pero v. m., que tiene belleza propia $i$ grandeza natural, no se desfigure por agradar al vulgo diziendo gracias i juegos del vocablo en poema grave i que va de veras. (Manuel M. Pérez, 1988, pp. 76-77)

Estamos claramente ante una percepción clasicista y adversa a la nueva poesía: Valencia recomienda que no se agrade al vulgo, al gusto de los tiempos nuevos en que se satisface en general a los modernos. Solicita así a don Luis que las metáforas guarden la analogía en la significación a que deben ajustarse, y solicita sobre todo que lo burlesco no se junte al estilo alto y al poema grave. Se postula pues la pureza y no la mezcla de los géneros: el poema grave de estilo alto se considera que no admite lo burlesco; ya don Ramón interpretó cómo Pedro de Valencia mantiene gustos de la centuria anterior con elogios - decía- «entre francos y sinuosos», es decir, mantiene gustos clasicistas del Quinientos. Tiene razón pues Orozco cuando piensa que Pedro de Valencia no siempre demuestra comprensión del arte de Góngora.

2. Las Advertencias de Andrés de Almansa y Mendoça para intelligencia de las Soledades de Don Luis de Góngora «fueron redactadas y difundidas en el verano de 1613» (Osuna, 2008, p. 54). En esencia tales Advertencias vienen a argumentar: 
a) «Dicen lo primero que a usado en las Soledades y Polifemo desiguales modos en su composición, y que devia el polifemo ser poesía lírica y las Soledades Heróyca, y que cambió los modos», dado que el Polifemo «canta una narración de un episodio», y las Soledades «por ningún camino podian ser heroicas [...] Vease que es una silva de varias cosas en la Soledad sucedidas, cuya naturaleza adequadam[en]te pedía la poesía lírica».

b) «Lo $2 .^{\circ}$ oponen que usa de bocablos nuevos, [...] y si alguna persona con justa causa puede ampliar la lengua es el Sr. don Luis que es dueño della, porque los valientes atrevimientos se conceden a los valientes ingenios». Y argumenta Almansa que en diez años el uso tendrá tales vocablos «connaturaliçados y recibidos», y que en las voces nuevas debe mirarse «su tenían propiedad, si estavan originadas de la lengua latina, si bien hispaniçadas», etc. Y

c) «Lo 3. ${ }^{\circ}$ dicen que no entienden la variedad de locuciones y de oraciones partidas[,] y que un ingenio tan claro que lo solía ser tanto, a querido no con alteza de conceptos sino con obscuridad de palabras hacer inaccesibles estas obras» (Orozco, 1969b, pp. 197-204).

El registro de género empleado, el neologismo, y la oscuridad, constituyen los motivos que recoge Andrés de Almansa de las habladurías y corrillos literarios del Madrid de los meses centrales de 1613, y a ellos contesta a su manera.

3. La dama boba de Lope tiene su autógrafo fechado el 28 de abril de ese año 13, y en la obra el dramaturgo creemos nosotros que respira por la herida de lo gongorino recién llegado, y no sólo incluye un soneto filosófico difícil —esto lo advirtió Dámaso Alonso-, sino que desecha la oscuridad y hace proscripción de ella, a saber: «iEscribe fácil!», expresa el personaje Nise, mientras Duardo proclama: «La claridad / a todos es agradable». La comedia lopeveguesca pensamos debe incorporarse a los textos de la polémica de las Soledades: Lope debió de sentirse muy inquieto y hasta desazonado en los meses centrales de 1613, desde luego cuando en abril escribió esta comedia.

4. Una carta fechada en Madrid el 13 de Septiembre de 1613 le llegó a Góngora a su retiro de Córdoba: es la «Carta que escriuieron a don Luis de Góngora en razón de las Soledades», e iba sin firma; Antonio Carreira postula esta datación, y en cuanto a su autoría y en general respecto de los momentos iniciales de la polémica de las Soledades postula: «La peregrina forma de producirse esta correspondencia, con papeles anónimos y volanderos encomendados a correveidiles, no excluye que algún partidario de cualquier bando terciase en la disputa» (Góngora, 1986, pp. 340-341). Estamos ante una interpretación en verdad prudente, ya que Orozco pensaba sin más que se trataba de «una solapada carta de Lope»; R. Jammes estima por su lado cómo la presente carta podría ser que hubiese emanado de algún amigo de Lope: las posturas entre los especialistas no se hallan tan distantes y no son tan distintas.

Este texto del 13 de Septiembre es el escrito que comienza: «Vn quaderno de versos desiguales y consonancias erráticas se ha aparecido en esta corte con nombre de Soledades, compuestas por vuesa merced». Toda la carta se halla compuesta en tono de absoluta burla, 
y así dice el para nosotros anónimo autor que —a la vista del poema que ha escrito-, y como

se cree que vuesa merced no ha participado de la gracia de Pentecostés, muchos se han persuadido que ha alcanzado algún ramalazo de la desdicha de Babel, aunque otros entienden que vuesa merced ha inventado esta jerigonça para rematar el seso de Mendoça: pues si tuuiera otro fin no lo hiziera tan dueño destas Soledades, teniendo tantos amigos doctos y cuerdos de quien pudiera vuesa merced quedar aduertido y ellas, enmendadas o declaradas, ya que de todo ello ay tanta necesidad. (Carreira, 1998, p. 251)

Bien se advierte en efecto la burla la carta, y la hiriente manifestación de que las Soledades precisan no sólo declaración o aclaración, explicación y glosa, sino enmienda. Se rechaza al correveidile Mendoza, y se rechaza la confusión u oscuridad que se derivan de la textura elocutiva del poema.

La ironía se prolonga en estos párrafos anónimos que se dicen en contra de los ingenios altivos, y que piden a don Luis no se proponga al escribir la dificultad de la construcción discursiva:

Y caso — no lo permita Dios - que vuesa merced por mostrar su agudeza quiera defender que mereze alabanza por inventor de difficultar la construción del romance, no se dexe caer vuesa merced en esta tentación, ya que tiene tantos exemplos de mil ingenios altiuos que se han despeñado por no reconoçer su primero disparate. Y pues las invenciones en tanto son buenas en quanto tienen de vtil, honroso y delectable lo que basta para quedar construidas en razón de bien, dígame vuesa merced si ay algo desto en esta su nouedad, por que yo convoque amigos que lo publiquen y la defiendan, que no setá pequeño seruicio, pues las más importantes siempre en sus principios tienen necessidad de valedores. (Ibid., pp. 252-253)

Horacianamente se pide al poeta cordobés lo «útil» y lo «deleitable», en medio — tal como decimos - de burlas y sarcasmos que pretenden descalificar mediante ironías e ingeniosidades. Se hace burla de Almansa y Mendoza y de las propias Soledades: no poco escándalo sarcástico debía correr por los corrillos poéticos.

5. Hay una carta de Góngora a la que se le ha dado valor de teoría o manifiesto: es la de 30 de Septiembre de 1613 justamente «en respuesta de la que le escribieron» el día 13 del mismo mes, o sea, en respuesta de la que acabamos de ver.

Don Luis replicó de inmediato y — según se ha dicho- con indignación despectiva e incluso no menos despectiva que la del escrito que le habían dirigido. Sus palabras llevan en sí efectivamente un manifiesto; alude a su modo poético, y entonces proclama: «Caso que fuera error, me holgara de haber dado principio a algo; pues es mayor gloria empezar una acción que consumarla» (los textos en Orozco, 1973, pp. 181-182). Siente que inicia algo, que es un innovador, y defiende esa innovación suya por la estética de la oscuridad que supone:

Hase de confesar que tiene utilidad avivar el ingenio, y eso nació de la obscuridad del poeta. [...] De honroso, en dos maneras considero me ha sido honrosa esta poesía; si enten- 
dida para los doctos, causarme ha autoridad, siendo lance forzoso venerar que nuestra lengua a costa de mi trabajo haya llegado a la perfección y alteza de la latina [...]. Demás que honra me ha causado hacerme escuro a los ignorantes, que esa es la distinción de los hombres doctos, hablar de manera que a ellos les parezca griego; pues no se han de dar las piedras preciosas a animales de cerda.

Don Luis justifica la poética de la oscuridad en cuanto despierta el ingenio del lector de poesía, pero además la justifica por una cuestión idiomática. A él le da autoridad ante los doctos tal oscuridad, y le da distinción de hombre docto, pues alcanza a hacer tan perfecto el castellano como sobre todo el latín, es decir, vuelve semejantes el latín y el castellano latinizado, la latinización gramatical y léxica hace iguales a la lengua de Castilla y a la del Lacio, y de esta manera ensalza la dignidad del romance igualando el hablar mostrenco con el de la sabia Antigüedad, de tal manera que en efecto »nuestra lengua a costa de mi trabajo ha [...] llegado a la perfección y alteza de la latina».

Se trata de que la misma perfección y por tanto logro o altura de la lengua latina puede alcanzarse en el idioma vernáculo si lo latinizamos o helenizamos (el acusativo griego): es un trabajo que causa autoridad a quien lo hace, según entiende Góngora. Entre las tareas idiomáticas que se le presentan a un autor del Seiscientos, se halla esta de la latinización de la lengua patrimonial para hacerla así igual a la lengua de Roma.

Insiste el lírico cordobés en la utilidad de avivar el ingenio, y en este sentido manifiesta en fin a la letra:

Si deleitar el entendimiento es darle razones que le concluyan y midan con su concepto descubriendo lo que está debajo de esos tropos, por fuerza el entendimiento ha de quedar convencido, y convencido, satisfecho: demás que como el fin de el entendimiento es hacer presa en verdades, que por eso no le satisface nada si no es la primera verdad, [...] en tanto quedará más deleitado cuanto, obligándole a la especulación por la obscuridad de la obra, fuera hallando debajo de las sombras de la obscuridad asimilaciones a su concepto.

Al margen de la alusión meramente demostradora de erudición —entendemos— al conocido texto agustiniano de que nuestro corazón se encuentra inquieto hasta que descanse en la primera verdad o verdad divina, nuestro autor vuelve a la idea de la utilidad y el deleite que provienen de vencer la oscuridad: aquí la utilidad del texto poético no es moral, sino que procede de la especulación que logra un vencimiento; la obra resulta útil, sí, pero útil para los doctos, y deleitosa para los doctos también. Ha de ser dulce y útil para los doctos, y esa utilidad resulta intransitiva y no trascendente; por supuesto que Góngora en la teoría no se refiera al moralizar y a los contenidos de pensamiento no quiere decir que sus versos se hallen faltos de contenidos morales y de una mentalidad que podríamos intentar analizar: ocurre que mantiene una poética muy estética, muy formal, una poética cultista que está en busca del idioma, de la ilustración del mismo hasta latinizarlo sobre todo y helenizarlo para hacerlo igual a los idiomas de la Antigüedad.

Góngora pues emula a los antiguos, haciendo que lo que no es latín sea como el latín: esta tarea de los modernos supera a la de esos antiguos, que ya tenían el latín dado en tanto lengua propia. 
Menéndez Pidal glosa cómo el procedimiento del decir encubierto pertenece a la poesía de todos los tiempos, pero que «su frecuencia o su continuidad es lo especial de la época barroca y sobre todo del gongorismo» (1966, p. 226).

6. Luego, del 16 de Enero de 1614 es otra carta que «es menos inverosímil» (Jammes) atribuir a Lope de Vega, escrita en «respuesta a las cartas de don Luis de Góngora y de don Antonio de las Infantas» y texto que Emilio Orozco tiene por un violento contraataque. Estamos en efecto ante palabras dichas en tono de burla otra vez, pues dicen por ej.: «Muy conocido es el gran trabajo que costaron a Vm. las Soledades», y ponen el poema en comparación con el gran trabajo que costó «a los embajadores Samios la oración afectada y prolija que hicieron a Lavoto», por lo que se les «reprehendió mucho del tiempo que en hacerla habían gastado» dado que no era de importancia ni le prestaban atención (los textos en Orozco, 1973, pp. 242 y 245): Lope lamenta por tanto y burlescamente en todo el contexto, el tiempo empleado en el trabajo de hacer algo sin importancia como las Soledades. La poética gongorina le parece a Lope un intento sin importancia, y no puede haber así —al menos en los manifiestos de doctrina- actitudes más enfrentadas que la lopeveguesca y la de Góngora; sin embargo Lope en algunos de sus textos sabido es que se gongorizará.

El dramaturgo echa abajo además la iniciativa que reclama para sí don Luis de latinizar y emular con la lengua latina:

Dice Vm. que ha sido el inventor de que nuestra lengua llegue a la alteza de la latina a costa de su trabajo, y habiendo de ser esto obligación tiene Vm. de imitar y igualar a los príncipes della, Cicerón y Virgilio, por su camino cada cual; de ninguno dellos se ha dicho jamás que es intricado y confuso, y de las Soledades lo dicen casi todos en general.

El emular con los antiguos ha de consistir en parecerse a ellos, y el autor cordobés no lo hace, precisamente por la confusión que deriva de la oscuridad. Podrá argumentarse que «hay otros autores latinos de oscuro y desabrido stilo» que han resultado bien admitidos, pero a ellos se les puede perdonar tal oscuridad y confusión «como quien toma una purga» por el provecho que se espera de ella, esto es, por sus «misteriosos conceptos», pero en el caso de las Soledades ocurre que «son tan superficiales sus misterios que entendiendo todos lo que quieren decir, ninguno entiende lo que dicen». O sea, que el poema gongorino, si se llega a entender, resulta que no dice nada y no se entiende y acaba por no entenderse eso que dice; no dice nada, es el resultado de un esfuerzo sin importancia, argumenta Lope en esta condena violenta. Con acierto glosa Orozco que «en la defensa de esa poesía de misteriosos conceptos, decubría la mejor razón en que él [Lope de Vega] había apoyado la creación de una poesía oscura de hondo contenido filosófico y estilo sencillo y natural en su vocabulario» (Ibid., pp. 235-236; D. Alonso ha comentado con gracia los esfuerzos creadores de don Luis al decir: «Debemos situarnos psicológicamente dentro de Lope cuando le empezó a caer el pedrisco que arreciaba desde Córdoba», o sea, cuando empezaron a conocerse las grandes creaciones gongorinas de la segunda época ).

Lope pretende echar abajo todo el esfuerzo del poeta de Córdoba, y así le argumenta la inutilidad del trabajo en latinizar el idioma, dado que el nuestro se encuentra ya en una situación adelantada o madura: es otra poética del lenguaje, la del uso del vernáculo por sí 
mismo en vez del empleo de una lengua patrimonial latinizada. Escribe se cree que Lope en este Enero del año 16:

No quiero dejar de decir a Vm. que he oído a muchos que no es perfección de nuestra lengua hacerla tan semejante a la latina, que obligue para entenderla a preceptos de construcción dificultosa, pues esto no es necesario y sólo es tomar lo peor de la latina, y si della se ha originado ya está tan adelantada que por sí sola es capaz de escribirse, y se escribe por diferentes modos de la latina y propios suyos que ya los ha adquirido, y se los han hallado sus escritores.

Nos encontramos con dos poéticas del idioma literario, con dos ideales del estilo: la poética de emular a los antiguos haciendo del castellano otro latín (Góngora), y la de escribir según los modos propios de la lengua patrimonial (Lope). Resultan así dos actitudes que tienen alguna semejanza con las respectivas de Alfonso X y de don Juan Manuel: más latinizante la primera, más atenta a producir estilo en el vernáculo por parte del segundo.

Esta toma de postura de quizá Lope ante Góngora no puede ser más negativamente asertiva, pues afirma la falta de importancia de lo que hace el cordobés, se mofa en el tono un tanto de él, y tiene por equivocados sus fundamentos estéticos; es un contraataque que no deja de tener su violencia o rotundidad en la argumentación, según hemos visto que estimaba Orozco.

7. Decididamente partidario en cambio de la poética y del arte gongorinos se manifiesta el Abad de Rute. Así en el «Parecer de Don Fran ${ }^{\text {co }}$ de cordova acerca de las Soledades a instancia de su Autor», escribe él respecto de las Soledades: que halla mucho bueno en ellas, de manera que no sabe por dónde acabar de loarlas (citamos el «Parecer...» por la ed. y estudio que hace del mismo Emilio Orozco Díaz, 1969b, pp. 132-134; 136-137; 139-144) .

No obstante le advierte y condena sobre la oscuridad: «Juzgo mi Señor — dice— que lo que a la hermosura destas Soledades [...] offusca, y haze sombra [...], es la obscuridad, quanto más affectada, y puesta en práctica, tanto más viciosa». La oscuridad — añade- es «culpable, y para ser huída», y nace en las «Soledades» de la demasía de tropos y figuras, «vizarras cada vna de por sí, y a trechos, y lugares convenientes; mas no para amontonadas»: es la acumulación de artificios la que lleva a la oscuridad, advierte el de Rute a don Luis, la voluntad desmesurada de estilo, el mucho barroco y barroquismo.

«La razón sola —insiste- bastara a persuadirnos el huir la obscuridad», y tras hacer mención del aprovechar y deleitar horaciano, desarrolla:

¿A quién a de aprovechar, y a quien deleitar lo que no es entendido? Dirá Vm. que se lo escribe para los doctos. Ya será eso conseguir sólo el fin menos principal, porque los doctos podrán bien deleitarse con este género y estilo de Poesía, pero aprovecharse no, siendo de cosas, que no deben ignorarlas. [...] Faltóle a esta obra para ser digna del ingenio de Vm (esto es perfectíssima) la perspicuidad ['claridad'], que es bondad, y requisito necesario [...], y es lástima que no sea tal ['de summa bondad'] obra de Vm. y en que se hallan tales, y tantos pedaços de belleza, sólo por querer su dueño que sea poco inteligible [...]. Así que no debe Vm. procurar escrevir para solos los doctos, porque desta suerte le entenderán y gustarán de sus obras muy pocos. 
Lo bueno por su propia naturaleza es comunicable a todos, luego las Soledades debían resultar claras para todos, y además lo bueno ha de serlo en todos sus componentes, luego asimismo en la elocución clara, en la claridad: así le razona don Francisco al autor cordobés.

El Abad de Rute le manifiesta de modo — diríamos — un tanto familiar y coloquial a Góngora: «No por amor de Dios, que a la verdad es terrible cosa, que en mi lengua materna aya yo de andar [... ] juntando partes, construyendo y adivinando, qué quiso dezir en aquello, o en esotro»: con franqueza y confianza, le pide sea claro y no caiga en oscuridad, pues caracteriza a los poetas mejores el buen artificio que parezca logrado sin esfuerzo: «El artificio del Poeta en lo que debe emplearse es en hazer y trabajar los versos de suerte que de fáciles qualquiera piense que podrá hazer otros tales, sin descubrir en ellos el arte y cuydado».

Un ejemplo de «claro estilo» — le advierte además el de Rute a Góngora- lo han dado «antiguos y modernos», y entre ellos «el divino Garcilaso»; con esta reflexión vuelve don Francisco a exhortar con confianza al autor cordobés: «Restituya Vm. a su casa la claridad [...] Vm. por amor de Dios se temple en esta parte, que como su servidor y amigo se lo suplico».

Don Francisco Fernández de Córdoba reprueba pues de manera categórica la oscuridad, aunque en general rebosa entusiasmo por la lírica gongorina: así lo estima el mejor especialista, Orozco, quien en particular interpreta cómo «querría [el Abad de Rute] que don Luis no extremara su afán de adorno; pero se complace en él» (Orozco, 1973, p. 152; Orozco, 1969b, p. 113).

Además de la reprobación de la oscuridad, este Parecer de don Francisco aborda también la cuestión de los neologismos, y postula por igual la moderación en su uso, de manera análoga a como ha recomendado la moderación en el empleo de tropos y figuras; se refiere el de Rute a cultismos latinos y a italianismos, y le expone a su amigo Góngora:

Lo mesmo deseo haga en el uso de palabras peregrinas, digo derivadas de latín y toscano; y no tanto en la muchedumbre dellas, pues todas son muy buenas, y a la verdad esto es enriquecer nuestra lengua y тиy conforme a los preceptos del arte [...] pero en el frecuentarlas y repetirlas muy a menudo, pues como a forasteras se a de ir poco a poco, y con recato, dándoles entrada y lugar señalado.

Reclama pues nuestro autor templanza en el uso de extranjerismos, y apela para tal cosa —entre otros autores con autoridad - a Aristóteles: «Aristóteles —recoge - concedió que caiese en los poetas agua de palabras forasteras, pero no que tempestate»). Resulta bien visible que también opone don Francisco a las Soledades la insistencia en el neologismo cultista o italianizante, que muchas veces don Luis recogía realmente de la tradición anterior.

Un tercer reparo concierne al hipérbaton y a la hipérbole, en cuyo empleo pide también moderación. Respecto del primero escribe el de Rute:

El Hiperbatón [...] sirve sin duda grandemente al ornato, turbando el orden de las palabras con anteposiciones y postposiciones, que realçan el hablar y le hazen numeroso ['cadencioso'], 
y nada vulgar [...]. Pero no a de ser todo Hiperbatón, [...] y así a mi juicio debe Vm. moderarse en él.

La objeción de don Francisco es la misma que respecto de los tropos, las figuras, y los neologismos: debe emplearse calma y moderación en el uso. «De la Hipérbole — dirá también- juzgo lo mesmo», y hace entonces una broma: «Si todo es en grado superlativo, ¿qué harán del positivo y comparativo los pobres gramáticos?».

En definitiva expone el Abad de Rute su parecer de que por medio de la hipérbole (o de cualquiera de los otros artificios) «no pierda lo verosímil el Poema», ya que en todo lugar —en todo momento— «la imitación poética debe seguir lo verosímil».

\section{4. $1635-1659$}

En lo histórico, podemos decir que nuestro Seiscientos consta de tres tercios: un primer tercio corto (Felipe III: 1598-1621); un segundo tercio largo (Felipe IV: 1621-1665); y el último tercio (Carlos II: 1665-1700). El gran esplendor de las letras ocurre en particular en 1605-1615, y en general en el primer tercio de la centuria considerado según lo cronológico estricto, es decir, hasta h. 1635; Menéndez Pidal estimaba así cómo «hacia 1637 se cierra pues el período de más hervor de tendencias, de mayor actividad y brillo en la producción literaria española», período —el iniciado hacia ese 1637— «de esfuerzo declinante» (2005, I, p. 1222).

Creemos sin embargo que no deben minusvalorarse y han de avalorarse los años que van desde final de ese primer tercio cronológico hasta hacia el final del reinado del cuarto Felipe, o sea, desde 1635 — digamos: guerra con Francia—, hasta 1659 - Paz de los Pirineos-: estamos ante años históricamente decisivos, pero además en los que en las letras se continúa la obra de Quevedo y de Calderón; escriben Saavedra Fajardo y Gracián; escriben asimismo María de Zayas, Vélez de Guevara, Martínez de Mata, el autor del Estebanillo...; la pintura cuenta con Velázquez y Murillo; etc.

Este cuarto de siglo 1535-1659 no debe quedar desdibujado, ni considerarse como de «declinación» en su importancia artística e histórica. Cabe reivindicar el presente cuarto de siglo y no simplificarlo, o sea, reivindicar por su importancia el relieve de los años del reinado de Felipe IV posteriores al último éxito de Nordlingen (1634), aunque fuesen años de derrota y de mutilación de la Monarquía.

Según decimos, la pintura y las letras —Quevedo, Calderón, Gracián, el Estebanillo, etc.-, lo avaloran: se trata así de un cuarto de siglo que se engloba en el que hemos denominado segundo y amplio tercio de la centuria.

El buen historiador varias veces mencionado antes Joan Reglà, en su exposición mencionada concretaba el contexto de estos años de un cuarto de siglo:

Olivares exigirá de España un esfuerzo sobrehumano para imponer el «austracismo»en Europa, mientras la falta de recursos [...] hace necesario alinear a los reinos no castellanos de 
la monarquía en la misma senda de sacrificios económicos de Castilla. [...En 1640] se producen los alzamientos de Cataluña y Portugal, instigados por los rivales de España, que a su vez revisten el triple carácter de guerras civiles, conflictos internacionales y revoluciones sociales. [...] El desmoronamiento es rápido: [Rocroi;] Westfalia, 1648; Pirineos, 1659; reconocimiento de la independencia de Portugal, 1665. [...]

El [...] viraje de Felipe II presidiría la constitución de un reducto español, forjado especialmente por Castilla, como un elemento diferenciado de la Europa moderna, es decir, de los países más o menos moldeados por el racionalismo filosófico y la burguesía capitalista. El choque decisivo entre ésta y las dos ramas de la Casa de Austria [...] tiene lugar precisamente durante la primera mitad del siglo xvii y se resuelve con el triunfo de la primera [...], que a su vez implica la quiebra de los odeales hispánicos y el planteamiento [...] de lo que la historiografía contemporánea llamaría el «problema» de España. (Reglá, 1963, pp. 291 y 318-319)

En el presente marco de gran relevancia histórico e ideológico, no disminuye grandemente lo artístico en los años de la guerra con Francia (1635-1659), según decimos: Velázquez, Murillo, Quevedo, Gracián, Saavedra Fajardo, Calderón, etc.

\section{REFERENCIA BIBLIOGRÁFICA DE LOS TEXTOS CITADOS (Y DE ALGUNO CONCORDANTE)}

Alborg, JuAn LuIs (I970). Historia de la literatura española. I., Madrid, Gredos, segunda ed. ampliada (esta Historia literaria tiene mayor enjundia —aunque también algunas caídas inevitables en texto tan extenso-, de lo que en ocasiones - y envidiosamente acaso- suele decirse).

Alborg, JuAn Luis (I970B). Historia de la literatura española. II., Madrid, Gredos, segunda ed.

Alonso Fernández, Dámaso (1978). «La lengua poética de Góngora», en sus Obras Completas, V, Madrid, Gredos.

Blanco, Mercedes (1992). Les Rhétoriques de la Pointe. Baltasar Gracián et le Conceptisme en Europe, Paris, Honoré Champion.

Blecua, José Manuel (I977). «Don Luis de Góngora, conceptista», en Sobre el rigor poético en España y otros ensayos, Barcelona, Ariel, pp. 83-90.

Boscán, Juan. Obras poéticas (I957) —ed. de M. de Riquer, A. Comas y J. Molas-, Facultad de Filosofía y Letras, Barcelona, pp. 87-91.

Carreira, Antonio (i998). «La controversia en torno a las Soledades. Un parecer desconocido, y edición crítica de las primeras cartas», en sus Gongoremas, Barcelona, Península, 1998, pp. 239-266.

Chevalier, Maxime (I992). Quevedo y su tiempo: la agudeza verbal, Barcelona, Crítica, aunque es lástima que este trabajo no tenga una exposición o conclusiones teóricas.

Delumeau, Jean (1977). La civilización del Renacimiento, Barcelona.

Góngora, Luis de (1986). Antología poética, ed. de Antonio Carreira, Madrid, Castalia.

Góngora, Luis de (19966 ). Fábula de Polifemo y Galatea, ed. de Alexander A. Parker, Madrid, Cátedra.

LÁzARo, Fernando (I97I). Lengua española: Historia, teoría y práctica, Salamanca, Anaya.

LÁzARo, Fernando (I984). Estilo barroco y personalidad creadora, Madrid, Cátedra, cuarta ed.

Maravall, José Antonio (i976). La cultura del Barroco, Barcelona, Ariel.

Maravall, José Antonio (I984). Estudios de Historia del pensamiento español. La época del Renacimiento, Madrid, Eds. Cultura Hispánica.

Menéndez Pidal, Ramón (I933). «El lenguaje del siglo xvi», Cruz y Raya, 6, 15 de Septiembre, pp. 7-63. 
MenÉndez Pidal, Ramón (i966). «Obscuridad, dificultad entre culteranos y conceptistas», recogido en su libro Castilla. La tradición, el idioma, Madrid, Espasa-Calpe, pp. 217-230.

MenÉndez Pidal, Ramón (2005). Historia de la lengua española, Madrid, Fundación Ramón Menéndez Pidal y Real Academia Española, I y II.

Orozco, Emilio (I953). Góngora, Barcelona, Labor.

Orozco, E. (1969). El teatro y la teatralidad del Barroco, Barcelona, Planeta.

Orozco Díaz, E. (1969B). En torno a las «Soledades» de Góngora, Universidad de Granada.

Orozco Díaz, E. (I973). Lope y Góngora frente a frente, Madrid, Gredos.

Osuna, M. a José (2008). Las 'Soledades' caminan hacia la corte, Vigo, Ed. Academia del Hispanismo.

Pfandl, Ludwig (1952). Historia de la literatura nacional española en la Edad de Oro, trad. esp., Barcelona, Gustavo Gili, segunda ed.

Pérez, Manuel María (i988). Pedro de Valencia, primer crítico gongorino, Universidad de Salamanca.

Parker, Alexander A. (I952). «La «agudeza» en algunos sonetos de Quevedo», Estudios dedicados a Menéndez Pidal, III, Madrid, CSIC, pp. 345-360.

REglá, JuAN y otros autores ( I963). Introducción a la Historia de España, Barcelona, Teide.

SKLOVSKIJ, VíKTOR (I9I7). «El arte como artificio», en Todorov (1970), pp. 55-70.

Todorov, Tzvetan, ed. (1970). Teoría de la literatura de los formalistas rusos, trad. esp., Buenos Aires, Eds. Signos.

Vossler, Karl (1929). Positivismo e idealismo en la lingüística. El lenguaje como creación y evolución, Madrid-Buenos Aires, Poblet.

Vossler, KARL (1963). Filosofía del lenguaje, Buenos Aires, Losada, cuarta edición. 